\title{
MENISCUS REGENERATION COMBINING MENISCUS AND MESENCHYMAL STROMAL CELLS IN A DEGRADABLE MENISCUS IMPLANT: AN IN VITRO STUDY
}

\author{
M.H. Hagmeijer ${ }^{1}$, L.A. Vonk ${ }^{1}$, M. Fenu ${ }^{1}$, Y.W.A.M. van Keep ${ }^{1}$, A.J. Krych ${ }^{2}$ and D.B.F. Saris ${ }^{1,2,3, *}$
}

${ }^{1}$ Department of Orthopaedics, University Medical Centre Utrecht, Utrecht University, the Netherlands

${ }^{2}$ Department of Orthopaedic Surgery, Mayo Clinic, Rochester, MN, USA

${ }^{3}$ MIRA Institute for Technical Medicine, University Twente, Enschede, the Netherlands

\begin{abstract}
Meniscus regeneration is an unmet clinical need as damage to the meniscus is common and causes early osteoarthritis. The aim of the present study was to investigate the feasibility of a one-stage cell-based treatment for meniscus regeneration by augmenting a resorbable collagen-based implant with a combination of recycled meniscus cells and mesenchymal stromal cells (MSCs).

Cell communication and fate of the different cell types over time in co-culture were evaluated by connexin 43 staining for gap junctions and polymerase chain reaction (PCR) to discriminate between meniscus cells and MSCs, based on a Y-chromosome gene. To define optimal ratios, human meniscus cells and bone-marrowderived MSCs were cultured in different ratios in cell pellets and type I collagen hydrogels. In addition, cells were seeded on the implant in fibrin glue by static seeding or injection.

Cellular communication by gap junctions was shown in co-culture and a decrease in the amount of MSCs over time was demonstrated by PCR. 20:80 and 10:90 ratios showed significantly highest glycosaminoglycan and collagen content in collagen hydrogels. The same statistical trend was found in pellet cultures. Significantly more cells were present in the injected implant and cell distribution was more homogenous as compared to the statically seeded implant.

The study demonstrated the feasibility of a new one-stage cell-based procedure for meniscus regeneration, using $20 \%$ meniscus cells and $80 \%$ MSCs seeded statically on the implant. In addition, the stimulatory effect of MSCs towards meniscus cells was demonstrated by communication through gap junctions.
\end{abstract}

Keywords: Meniscus injury, meniscus regeneration, bone marrow mesenchymal stromal cells, meniscus cells, meniscus scaffold, collagen meniscus implant.

*Address for correspondence: Daniel Bart Frederik Saris, University Medical Centre Utrecht, Heidelberglaan 100, 3584 CX Utrecht, the Netherlands.

Telephone number: +31 887559025 Email: Saris.Daniel@mayo.edu

Copyright policy: This article is distributed in accordance with Creative Commons Attribution Licence (http://creativecommons.org/licenses/by-sa/4.0/).

\section{Introduction}

Meniscus tissue is characterised by low cell density and a dense extracellular matrix (ECM), which mainly consists of water, type I collagen, glycosaminoglycans (GAGs) and elastin (Fox et al., 2015a). With their semilunar wedge-shaped structure, the menisci play an important role in shock absorption, load transmission and stability of the knee (Fox et al., 2015; Masouros et al., 2008). Damage to the meniscus is a very common injury, which leads to loss of its chondroprotective role in the knee. Especially in young patients with high activity levels (Mitchell et al., 2016; Verdonk et al., 2016), loss of meniscus function can lead to an increased risk of developing early osteoarthritis (OA) (Englund et al., 2009;
Masouros et al., 2008). (Partial) meniscectomy used to be the first choice of treatment for meniscus tears; however, due to the high risk of developing postmeniscectomy OA secondary to increased contact pressure on cartilage (Englund et al., 2009; Verdonk et al., 2016), meniscus repair is becoming more popular. Meniscus repair is not suitable for all types of tears. Therefore, meniscus restorations using allograft transplantation or biodegradable meniscus scaffolds are of interest (Dangelmajer et al., 2017; Filardo et al., 2015).

Currently, the clinically-available acellular meniscus implant is the collagen meniscus implant $\left(\mathrm{CMI}^{\circledR}\right)$ (Stryker, Kalamazoo, MI, USA). This implant has a porous structure providing an environment for cell ingrowth. Clinical results after implantation 
of the $\mathrm{CMI}^{\circledR}$, evaluated by patient-reported outcome measures (PROMs), are promising, with a postoperative increase of the Lysholm score and Tegner activity scale and a decrease in visual analogue scale (VAS) pain for up to ten years (Filardo et al., 2015; Grassi et al., 2014; Zaffagnini et al., 2015). However, limited engraftment and neo-tissue formation by invading cells can lead to size reduction of the regenerated meniscus, consequently allowing the opportunity for improvement of this treatment (Pabbruwe et al., 2010). The present study proposed that replacing the deficient segment of a meniscus with a cell-seeded meniscus implant led to improved, more consistent and better-distributed functional new meniscus-like tissue formation.

The numbers of meniscus cells recovered from the resected meniscus, even during an overnight digestion, are relatively low and not suitable for engraftment $\left[ \pm 1.5 \times 10^{3}\right.$ cells/mg meniscus (Hagmeijer et al., 2018)]. It would be cost effective, causing lower patient burden and being logistically attractive to use these cells in a one-stage procedure for meniscus regeneration. Recently, a clinical study has shown the safety and feasibility of using a combination of recycled autologous chondrons with allogeneic mesenchymal stromal cells (MSCs) for cartilage repair (de Windt et al., 2017a; de Windt et al., 2017b). This and other studies have suggested that allogeneic MSCs provide stimulatory and immunomodulatory factors for tissue repair and are able to positively stimulate a smaller number of meniscus cells, as an alternative to engraftment and differentiation (Caplan and Correa, 2011; Prockop and Youn Oh, 2012; Schepers and Fibbe, 2016). For these reasons, allogeneic MSCs have even outperformed autologous MSCs in a comparative human study for the treatment of nonischemic dilated cardiomyopathy (Hare et al., 2017).

The goal of the present in vitro study was to assess the conditions for a new one-stage treatment of meniscus damage. To achieve this goal, three main questions were analysed:

1) Do MSCs and meniscus cells communicate?

2) What ratio of MSCs to meniscus cells is optimal for the production of native-like meniscus tissue?

3) What is the optimal method for delivering the cells uniformly into a clinically applicable scaffold?

\section{Materials and Methods}

\section{Donors and cell isolation}

Tissue from whole meniscus was obtained from the redundant material of 11 patients that had undergone total knee replacement [mean age 65.9 (range 55-73) years, 4 male and 7 female]. Collection of this patient material was performed according to the Medical Ethical regulations of the University Medical Centre Utrecht and the guideline "good use of redundant tissue for research" of the Dutch Federation of Medical Research Societies (van Diest, 2002; FEDERA, 2011). Meniscus tissue was rinsed in phosphate buffered saline (PBS) with $100 \mathrm{U} / \mathrm{mL}$ penicillin (Gibco) and $100 \mu \mathrm{g} / \mathrm{mL}$ streptomycin (Gibco) (1\% pen/strep), cut into pieces of $2 \mathrm{~mm}^{3}$ and digested overnight at $37{ }^{\circ} \mathrm{C}$ in $0.15 \%$ collagenase type 2 (CLS-2, Worthingtom, Lakewood, NJ, USA) in Dulbecco's modified Eagle's medium (DMEM; Gibco) and $1 \%$ pen/strep. Meniscus cells were expanded for one passage in DMEM supplemented with $10 \%$ foetal bovine serum (FBS; HyClone, Logan, UT, USA) and $1 \%$ pen/strep (Verdonk et al., 2016) and used as passage 1 in all experiments.

Human MSCs (hMSCs) were isolated from bone marrow biopsies from the iliac crest during total hip replacement from 6 patients after written informed consent was obtained (Medical Ethical Committee, University Medical Centre Utrecht) as described previously (Gawlitta et al., 2012). Cells were expanded in $\alpha$-MEM (minimal essential medium, Gibco) supplemented with $10 \%$ FBS, $1 \% 20$ mM 1-ascorbic acid-2-phospate (1\% ASAP; Sigma-Aldrich) and $1 \%$ pen/strep to be used at passage 3. Meniscus cells and MSCs from different donors were not pooled.

\section{Fluorescent dye transfer}

To assess gap-junction-mediated communication between hMSCs and meniscus cells, fluorescent dye transfer was used (Asklund et al., 2003). $10 \mu \mathrm{M}$ Vybrant CM-DiI (Molecular Probes) and $10 \mu \mathrm{M}$ calcein-AM (Molecular Probes) were diluted in PBS and incubated with either meniscus cells or hMSCs for $1 \mathrm{~h}$ at $37^{\circ} \mathrm{C}$. Afterwards, cells were washed with PBS and co-cultured in a $50: 50$ ratio for $36 \mathrm{~h}$ as a monolayer in a 96-well plate. Gap junctions were assessed by fluorescence microscopy (EVOS Cell Imaging System, ThermoFisher Scientific) after 24 and $36 \mathrm{~h}$ of culture through transfer of calcein-AM. 3 meniscus donors and 3 MSC donors were used for the experiment; all were combined and 3 technical replicates per condition were performed.

\section{Cell pellet formation}

Cells were counted with an automated cell counter (TC20TM, Bio-Rad) at $1: 1$ dilution in trypan blue (Bio-Rad). Cell suspensions were prepared at the concentrations of $0 \%, 10 \%, 20 \%, 25 \%, 50 \%$, $75 \%$ and $100 \%$ meniscus cells combined with hMSCs. In a U-bottom 96-well plate (Greiner BioOne, CELLSTAR ${ }^{\circledR}$ ), a total of 250,000 cells per well and $200 \mu \mathrm{L}$ of differentiation medium [DMEM, supplemented with $1 \%$ pen/strep, $2 \% 20$ mM ASAP, $2 \%$ insulin-transferrin-selenium-X (ITSX, Invitrogen) and $2 \%$ human serum albumin (HSA; Sanquin, Utrecht, the Netherlands)] were centrifuged for $5 \mathrm{~min}$ at $300 \times g$ to form pellets. Cell pellets were cultured for $28 \mathrm{~d}$ at $37^{\circ} \mathrm{C}$ with $5 \% \mathrm{CO}_{2}$; medium was changed 3 times per week and conditioned medium was stored at $-20{ }^{\circ} \mathrm{C}$ for biochemical analysis.

\section{Type I collagen hydrogel preparation}

Cell concentrations with $0 \%, 10 \%, 20 \%, 50 \%$ and $100 \%$ meniscus cells were prepared in suspension 
Table 1. Primers' sequences used for PCR.

\begin{tabular}{|c|c|c|c|}
\hline \multicolumn{2}{|c|}{ Target gene } & Oligonucleotide sequence & $\begin{array}{c}\text { Annealing } \\
\text { temperature }\left({ }^{\circ} \mathrm{C}\right)\end{array}$ \\
\hline \multirow{2}{*}{$18 S$} & Forward & ${\text { 5' GTAACCCGTTGAACCCCATT } 3^{\prime}}^{\prime}$ & \multirow{2}{*}{58} \\
\hline & Reverse & $5^{\prime}$ CCATCCAATCGGTAGTAGCG 3' & \\
\hline \multirow{2}{*}{ KDM5D } & Forward & 5' TAACACACACCCGTTTGACAA 3' & \multirow{2}{*}{60} \\
\hline & Reverse & 5' GCTGCTGAACTTTGAAGGCTG 3' & \\
\hline \multirow{2}{*}{ UTY } & Forward & 5' CACAAAGAAGTTGCTCAGGTACG 3' & \multirow{2}{*}{60} \\
\hline & Reverse & 5’ TGTGGTTGTCGATTAGAGACAGA 3' & \\
\hline
\end{tabular}

with hMSCs, using the same concentrations as for the cell pellets. Collagen gels were prepared from rat tail type I collagen (Corning) with a final collagen concentration of $2 \mathrm{mg} / \mathrm{mL}$ per hydrogel; $2.5 \mu \mathrm{L}$ of $5 \mathrm{M}$ $\mathrm{NaOH}$ were mixed with $800 \mu \mathrm{L}$ of collagen solution $(2.5 \mathrm{mg} / \mathrm{mL}$ in $0.02 \mathrm{~N}$ acetic acid). Cell suspensions were added, $100 \mu \mathrm{L}$ of the combined solution was transferred to different wells of a 12-well plate with a cell concentration of 250,000 cells in $200 \mu \mathrm{L}$ and incubated for $60 \mathrm{~min}$ at $37^{\circ} \mathrm{C}$. Subsequently, $2 \mathrm{~mL}$ of differentiation medium were added. Hydrogels were cultured for $28 \mathrm{~d}, 1 \mathrm{~mL}$ of medium was changed 3 times per week and stored at $-20{ }^{\circ} \mathrm{C}$ for future biochemical analysis.

\section{Polymerase chain reaction (PCR)}

Cell pellets, fibrin glue constructs and collagen type I gel constructs of i) monoculture meniscus cells and hMSCs and ii) co-culture of $20 \%$ meniscus cells and $80 \% \mathrm{hMSC}$ s were harvested at $\mathrm{t}=0 \mathrm{~d}(4$ constructs per condition), $\mathrm{t}=14 \mathrm{~d}$ (4 constructs per condition) and $\mathrm{t}=28 \mathrm{~d}$ (4 constructs per condition) for PCR analysis. Total RNA was isolated using TRIzol reagent (Invitrogen), as described by the manufacturer. Total RNA (500 ng) was reverse transcribed using the highcapacity cDNA Synthesis Kit (Applied Biosystems). PCR was performed on 5x-diluted cDNA using iTaq Universal SYBR Green Supermix (Bio-Rad) in a LightCycler 96 (Roche Diagnostics) according to the manufacturer's instructions.

In the co-cultures used for PCR, all meniscus donors were female and all MSC donors were male; therefore, during the PCR, using primers for the genes on the $\mathrm{Y}$ chromosome, a distinction could be made between the different cell types. The housekeeping gene $18 S$ was used and primers for lysine demethylase 5D (KDM5D) and ubiquitously transcribed tetratricopeptide-repeat-containing, Y-linked (UTY) were used to amplify the $Y$ chromosome (Table 1) and, therefore, the MSCs in the co-cultures.

\section{Biochemical analysis}

After an overnight digestion of the samples in papain buffer $[250 \mu \mathrm{g} / \mathrm{mL}$ papain (Sigma-Aldrich), $0.2 \mathrm{M}$ $\mathrm{NaH}_{2} \mathrm{PO}_{4}, 0.1 \mathrm{M}$ EDTA, $0.01 \mathrm{M}$ cysteine] at $60{ }^{\circ} \mathrm{C}$, GAG content was determined by dimethylmethylene blue (DMMB) assay. Absorption ratio was set at 525 and $595 \mathrm{~nm}$ using chondroitin sulphate (SigmaAldrich) as a standard for calculating GAG content.
DNA content was determined by Picogreen DNA assay (Invitrogen), according to the manufacturer's instructions. Excitation and emission were set at 480 and $520 \mathrm{~nm}$, respectively, and $\lambda$ DNA was used as a standard reference to calculate DNA content. Freeze-dried papain samples were used to determine collagen content of the constructs by hydroxyproline assay. $100 \mu \mathrm{L}$ of $1.4 \mathrm{M}$ citric acid (27490; Fluka) was added following overnight hydrolysis of the samples in $100 \mu \mathrm{L}$ of $4 \mathrm{M} \mathrm{NaOH}$ (6498; Merck) at $108{ }^{\circ} \mathrm{C}$. Choramine-T reagent (2426; Merck) and dimethylaminobenzoaldehyde (3058; Merck) were added to the samples and hydroxyproline standard (104506.0010; Merck) was used to measure the absorption at $570 \mathrm{~nm}$. As $13.5 \%$ of collagen is composed of hydroxyproline, the amount of collagen was calculated from the hydroxyproline content (Neuman and Logan, 1950).

\section{Histology and immunohistochemistry}

Samples were fixed in $4 \%$ buffered formaldehyde, dehydrated in graded ethanol series, immersed in xylene, embedded in paraffin wax, cut in $5 \mu \mathrm{m}$ thick sections and stained. Before staining and immunohistochemistry, sections were deparaffinised in xylene and rehydrated in ethanol. To determine cell distribution throughout the construct, sections were stained with Mayer's haematoxylin (Merck) and counterstained with eosin (Merck) (H\&E staining). To evaluate proteoglycan content, $0.125 \%$ safranin $\mathrm{O}$ (Merck) counterstained with Weigert's haematoxylin (Klinipath, Duiven, the Netherlands) and $0.4 \%$ fast green (Merck) was used. Picrosirius red (Klinipath, Leuven, Belgium)/alcian blue (SigmaAldrich) staining was used to visualise collagen fibre orientation by polarised light microscopy.

After rehydration, sections for connexin 43 , type I and II collagen immunohistochemistry were blocked for $10 \mathrm{~min}$ with $0.3 \% \mathrm{H}_{2} \mathrm{O}_{2}$ solution and washed with PBS-0.1\% Tween 20 (Sigma-Aldrich). Antigen retrieval was performed using $1 \mathrm{mg} / \mathrm{mL}$ pronase (Roche) in PBS and $10 \mathrm{mg} / \mathrm{mL}$ hyaluronidase (Sigma-Aldrich) in PBS, both for $30 \mathrm{~min}$ at $37^{\circ} \mathrm{C}$. Sections were blocked with $5 \%$ PBS/bovine serum albumin (BSA) for $30 \mathrm{~min}$ at room temperature, followed by incubation with primary antibodies for either connexin 43 (GJA1, rabbit polyclonal antibody, 1 : 50 in PBS/5 \%BSA, Abcam), type I collagen (Col1, rabbit monoclonal antibody, 1 : 400 in PBS/5 \% BSA, Abcam) or type II collagen (II-II6B3, mouse monoclonal antibody, 
1 : 100 in PBS/5 \% BSA, DSHB, Merck). As negative controls, rabbit IgG (Dako) was used for connexin 43 ( 1 : 2,000 in PBS/5 \%BSA) and type I collagen (1 : 10,000 in PBS/5 \%BSA) and mouse IgG (1 : 100 in PBS/5 \% BSA, Dako) for type II collagen. Antibodies were incubated overnight at $4{ }^{\circ} \mathrm{C}$ and, subsequently, washed in $0.1 \%$ PBS-Tween 20 and incubated with the secondary antibody for connexin 43 [goat anti-rabbithorseradish peroxidase (HRP) 1 : 100 in PBS/5 \% BSA; 3117332001; Roche], type I (EnVision + System-HRP, goat anti-rabbit; K4003, Dako) and type II (goat anti-mouse IgG HRP, 1 : 100 PBS/5 \% BSA; P0447, Dako) collagen for 60,30 and $60 \mathrm{~min}$, respectively, at room temperature. Immunoreactivity, visualised with 3-diaminobenzidine (DAB, Sigma-Aldrich), was stopped using MilliQ water (Merck). Sections were counterstained with Mayer's haematoxylin diluted $1: 1$ in distilled water, dehydrated in different gradients of ethanol and mounted in Depex (Merck).

\section{Seeding methods}

$\mathrm{CMI}^{\circledR}$ pieces (with a size of approximately $150 \mathrm{~mm}^{3}$ ) were seeded with $10 \%$ meniscus cells and $90 \%$ hMSCs, based on successful results using chondrons and MSCs in the same ratio (Bekkers et al., 2013). Before seeding, the $\mathrm{CMI}^{\circledR}$ was washed for $10 \mathrm{~d}$ in $100 \mathrm{~mL}$ PBS with $1 \%$ pen/strep. The fibrin glue (Beriplast, CSL Behring) used was diluted as described by Abbadessa et al. (2016) and all cells were mixed in the fibrinogen component of the fibrin glue. After seeding and incubation, scaffolds were moved to a new 24-well plate (to exclude cells not attached to the scaffold) for subsequent calculation of matrix production and cell-count. Seeded constructs were cultured for $26 \mathrm{~d}$ in $1 \mathrm{~mL}$ of differentiation medium, which was changed 3 times per week and stored for biochemical analysis.

To mimic the clinical circumstances of ex vivo and in vivo seeding during arthroscopy, two different seeding techniques were used. Static surface seeding was performed on dry $\mathrm{CMI}^{\circledR}$, resembling ex vivo seeding. $75 \mu \mathrm{L}$ of cell suspension in fibrinogen, containing a total of $5.0 \times 10^{5}$ cells $\left(5.0 \times 10^{4}\right.$ meniscus cells and $4.5 \times 10^{5} \mathrm{hMSC}$ ), were loaded on top of the $\mathrm{CMI}^{\circledR}$, immediately followed by $75 \mu \mathrm{L}$ of thrombin and incubation for $15 \mathrm{~min}$ at $37^{\circ} \mathrm{C}$. Seeding by injection was executed on wet $\mathrm{CMI}^{\circledR}$, immersed in $1 \mathrm{~mL}$ of PBS in a 24-well plate, resembling in vivo seeding after

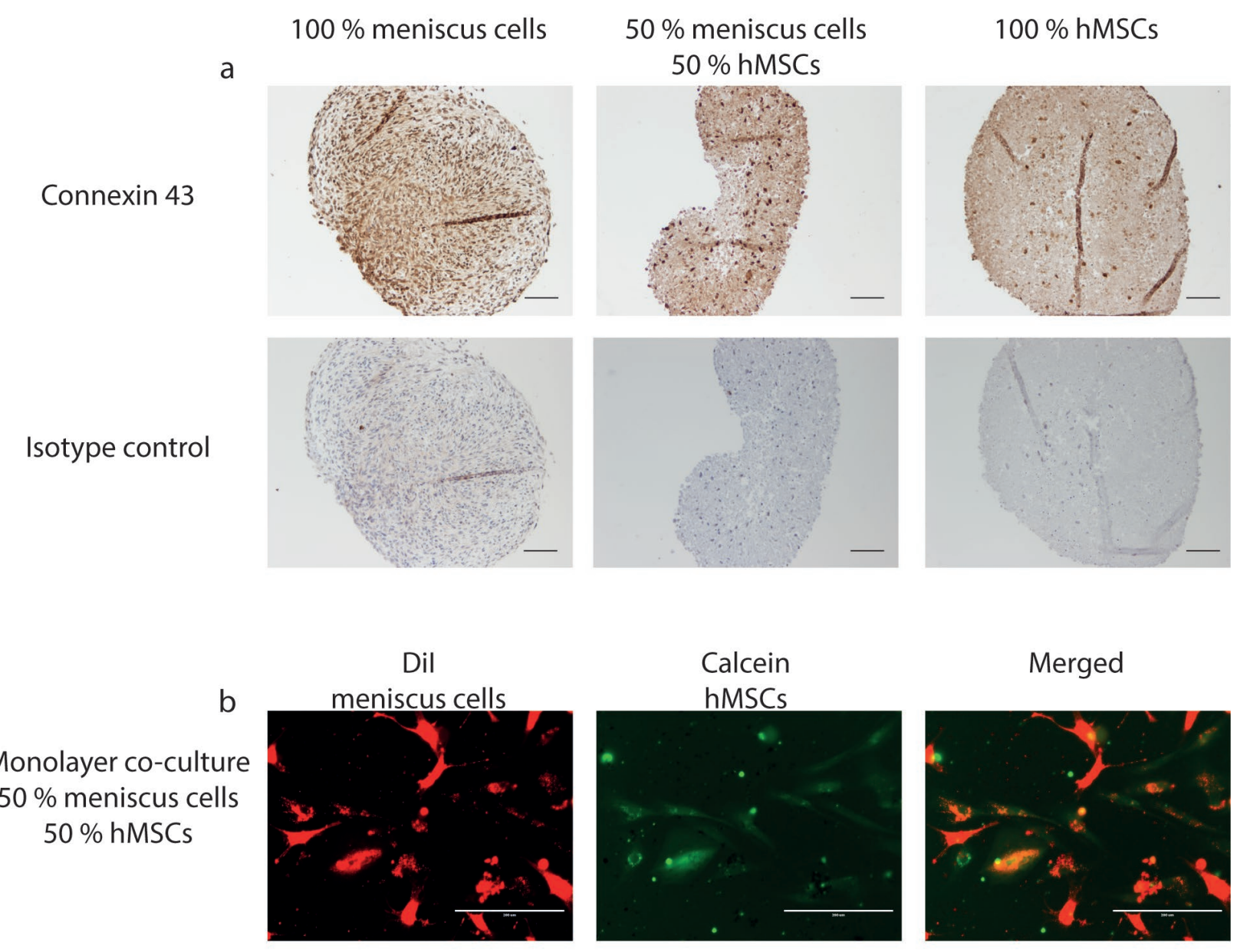

Fig. 1. Cell-cell communication. Cell-cell communication by gap junctions between hMSCs and meniscus cells was determined by (a) the presence of connexin 43 in mono- and co-cultures in pellets after $28 \mathrm{~d}$ and (b) dye transfer : Vybrant CM-DiI (red), calcein (green) and an overlay of Vybrant CM-DiI and calcein (merged), where transfer of the calcein stained hMSCs to the meniscus cells stained with Vybrant CM-DiI is shown after $24 \mathrm{~h}$. Scale bar: $200 \mu \mathrm{m}$. 

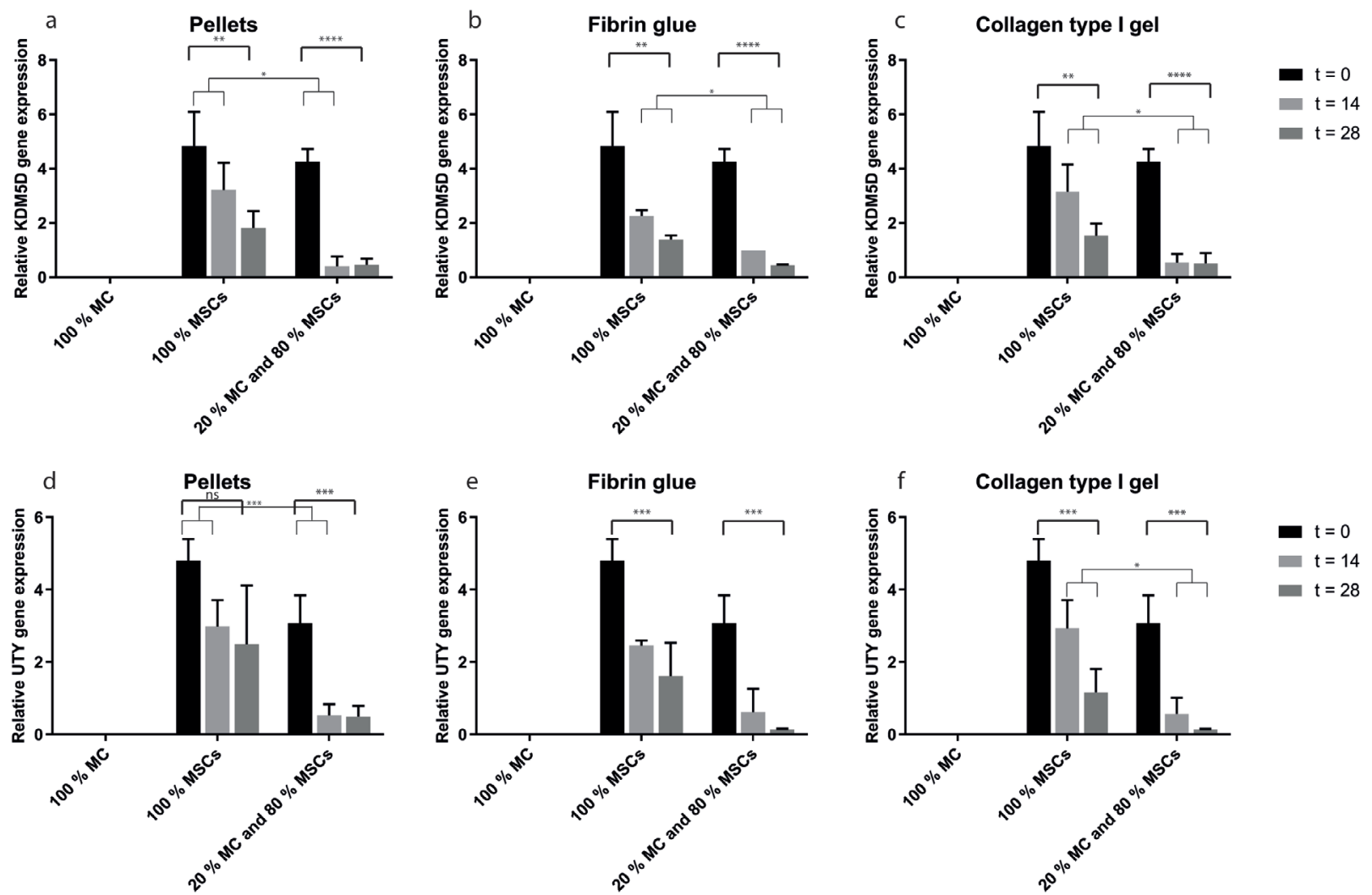

Fig. 2. PCR data after (co)culture of meniscus cells and MSCs. (a-c) PCR data for both KDM5D and (df) UTY, representing the Y-chromosome genes in the male MSCs, showed a decrease in the amount of MSCs over time. Absolute difference between $t=0 \mathrm{~d}$ and $\mathrm{t}=28 \mathrm{~d}$ was calculated for both monocultures of MSCs and co-culture of MSCs and meniscus cells (ratio $80: 20$ ). The delta of the mean decrease per culture condition was calculated and significant differences between monocultures of MSCs and co-cultures of MSCs with meniscus cells are marked with brackets. ${ }^{*} p<0.05 ;{ }^{* *} p<0.01 ;{ }^{* *} p<0.001 ;{ }^{* * *} p<0.0001$. MC: meniscus cells. ns: not significant.

arthroscopic implantation of the scaffold. Using a $1.0 \mathrm{~mL}$ syringe and a 23-gauge needle, $75 \mu \mathrm{L}$ of cell suspension $\left(5.0 \times 10^{5}\right.$ cells, similar cell combination to static surface seeding) were injected into the $\mathrm{CMI}^{\circledR}$ and incubated at $37^{\circ} \mathrm{C}$ for 15 min after injection of $75 \mu \mathrm{L}$ of thrombin using a 23-gauge needle.

\section{Cell distribution assessment using confocal microscopy}

Accessing cell distribution throughout the $\mathrm{CMI}^{\circledR}$ after $26 \mathrm{~d}$ of culture using the different seeding methods was performed by creating three-dimensional (3D) images acquired by a Leica SP8 confocal microscope. Two pieces of $\mathrm{CMI}{ }^{\circledR}$ per seeding method were stained for $30 \mathrm{~min}$ with $0.5 \mu \mathrm{L} / \mathrm{mL}$ calcein AM (Molecular Probes) at room temperature and for $4 \mathrm{~min}$ with $100 \mathrm{ng} / \mathrm{mL}$ 4',6-diamidino-2-phenylindole (DAPI) followed by washing with PBS. A tile scan with z-stack was performed and the 3D images were merged using Image J.

\section{Statistical analysis}

Statistical analyses were performed using GraphPad Prism 7.02 (GraphPad Software Inc., La Jolla,
CA, USA). Differences in GAG and collagen per DNA for the different ratios and seeding methods were calculated by a one-way analysis of variance (ANOVA) and Tukey's multiple comparisons test. The decrease in KDM5D and UTY per culture condition at the different time points were calculated using a student's $t$-test. To determine whether there was a significant difference in relative decrease in the amount of MSCs between monoculture of MSCs and co-culture of MSCs and meniscus cells over time, the delta of the mean decrease per condition was calculated and student's $t$-tests were performed. $p<0.05$ was considered statistically significant.

\section{Results}

Communication and cell survival in co-cultures Immunohistochemistry for connexin 43 in the pellet co-cultures showed staining for the monocultures of meniscus cells and hMSCs as well as for the different ratios of the co-cultures (Fig. 1a), indicating formation of gap junctions in both mono- and co-cultures. When hMSCs were stained with calcein and meniscus 
cells with Vybrant CM-DiI, the dye transfer was shown most prominently by the yellow staining of the red meniscus cells, which also stained for the calcein transferred from the hMSCs (Fig. 1b). When hMSCs were incubated with Vybrant CM-DiI and the meniscus cells with calcein, the dye transfer was less prominent. This suggested that there was active gap-junction-mediated communication, which was more active from hMSCs to meniscus cells than from meniscus cells to hMSCs.

PCR data of monoculture hMSCs and co-culture with meniscus cells, in either pellet, fibrin glue and type I collagen gel, showed a significant decrease in KDM5D and UTY over time for both mono and cocultures and, therefore, a decrease in the amount of hMSCs over time (Fig. 2). The decrease in co-cultures was higher as compared to the decrease in hMSCs monocultures. In addition, in pellet culture, the decrease of hMSCs was significantly lower (KDM5D, $p=0.013$; UTY, $p=0.0006$ ) between $\mathrm{t}=0 \mathrm{~d}$ and $\mathrm{t}=14 \mathrm{~d}$ for monoculture of hMSCs as compared to co-culture. Whereas between $\mathrm{t}=14 \mathrm{~d}$ and $\mathrm{t}=28 \mathrm{~d}$, the mean decrease in hMSCs was higher in monoculture for cultures in fibrin glue and type I collagen (fibrin glue: KDM5D $p=0.0427$, UTY $p=0.4762$; type I collagen: KDM5D $p=0.0448$, UTY $p=0.0193$ ) (Fig. 2).

\section{Production of ECM in pellet co-cultures}

Biochemical analysis showed a significant decrease in DNA content of cell pellets ( $n=5$ for biological replicates and $n=3$ for technical replicates) after 4 weeks of culture for the ratios containing a percentage of hMSCs (Fig. 3a). The larger the proportion of hMSCs, the fewer cells were present after $28 \mathrm{~d}$ of culture. The ratios with more than $50 \%$ hMSCs produced significantly more GAG content per DNA as compared to $100 \%$ meniscus cells (Fig. 3b), which indicated a stimulatory effect of hMSCs on meniscus cell GAG, followed by meniscus cell apoptosis. The same assumption was demonstrated by PCR. In assessment of total GAG content of the samples combined with GAG in the medium, there were no differences observed for total GAG production. However, co-cultures with hMSCs seemed to perform better than monoculture of meniscus cells (Fig. 3c). Also, a trend for a higher collagen content in the cell pellets was suggested when the proportion of hMSCs was larger. However, results were not statistically significant (Fig. 3d).

In H\&E staining, pellets containing $50 \%, 80 \%$ and $100 \%$ meniscus cells had a higher cell density (Fig. 4a), which was similar to the results for DNA quantification (Fig. 3). None of the cell ratios stained for GAG, indicating that the amount of GAG was too low to be detected histologically (data not shown). Immunohistochemistry showed a more intense DAB staining for type I collagen as compared to type II collagen. These findings, i.e. a low amount of GAG and higher presence of type I as compared to type II collagen, were characteristic of native meniscus tissue (Fig. 4b,c).

\section{Production of ECM in collagen type I hydrogels}

After 4 weeks of co-culturing meniscus cells and hMSCs in type I collagen hydrogels $(n=3$ for both biological and technical replicates), DNA content was not statistically significantly different among the different conditions (Fig. 3e). GAG content and total GAG production, both normalised to DNA content, were the highest $(p<0.001$ and $p<0.05$, respectively) in $20 \%$ meniscus cells and $80 \%$ hMSCs as compared to the other ratios (Fig. 3f,g). A trend of more GAG production was observed in the hydrogels containing $>50 \%$ hMSCs as compared to > 50 \% meniscus cells, although not all results were statistically significant. Collagen content, corrected for DNA, showed a significantly higher concentration in the conditions with $90 \%$ and $100 \%$ hMSCs (Fig. 3h).

Histology showed an even distribution of cells throughout the different constructs; however, no proteoglycan content was detected. Immunohistochemistry showed a larger presence of type I collagen as compared to type II collagen (data not shown), similar to the pellet culture.

\section{Optimal in vitro seeding method}

Immediately after seeding, the wet-injected $\mathrm{CMI}^{\circledR}$ contained significantly fewer cells than the total number of seeded cells $(p=0.0070)$ and the drystatically-seeded CMI ${ }^{\circledR}(p=0.0096)$. The number of cells in the dry-and statically-seeded $\mathrm{CMI}^{\circledR}$ were not statistically different from the total number of seeded cells ( $p=0.6899)$ (Fig. 5a). After $26 \mathrm{~d}$ of culture $(n=3$ for both biological and technical replicates), the $\mathrm{CMI}^{\circledR}$ seeded statically in a dry environment showed a significantly higher DNA content as compared to the $\mathrm{CMI}^{\circledR}$ injected in a wet environment $(p=0.0491)$ (Fig. $5 b)$. GAG content appeared to be slightly higher in the first group although the data were not statistically significant ( $p=0.7249$ ) (Fig. 5c). GAG release into the medium was significantly higher in the dry- and statically-seeded $\mathrm{CMI}^{\circledR}(p=0.0306)$ (data not shown). Because the $\mathrm{CMI}^{\circledR}$ is composed of bovine collagen, the produced collagen content was determined using the ratio of collagen before and after culture corrected for an empty $\mathrm{CMI}^{\circledR}$. This resulted in no significant differences among the different seeding methods $(p=0.3426)$. Histological analyses showed a better cell distribution within the scaffold for the dry-seeded $\mathrm{CMI}^{\circledR}$ as compared to the wet-seeded scaffolds. Fig. 6 shows histology of the dry-seeded $\mathrm{CMI}^{\circledR}$, with a good cell distribution shown by H\&E staining in Fig. 6a. However, no proteoglycans were detected by histology (Fig. 6b). Immunohistochemistry showed a high production of type I collagen and only minimal deposition of type II collagen (Fig. 6c,d), which was similar to native meniscus tissue. 3D confocal images confirmed the homogenous distribution of cells throughout the whole $\mathrm{CMI}^{\circledR}$ when the scaffold was seeded dry and statically (Fig. 7a), whereas for the wet-injected $\mathrm{CMI}^{\circledR}$, there were only pockets of cells visible (Fig. 7b). 


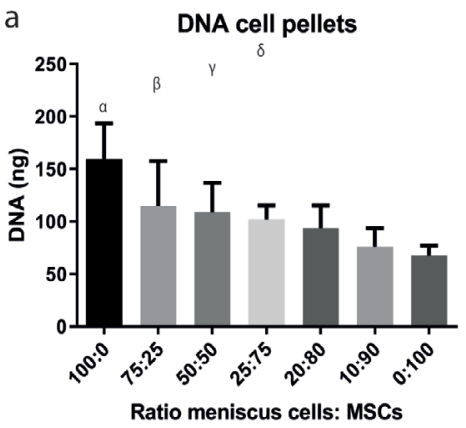

b

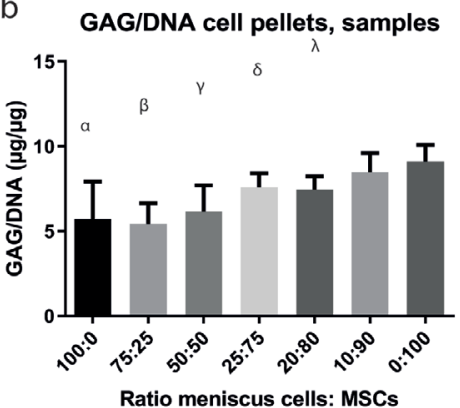

C

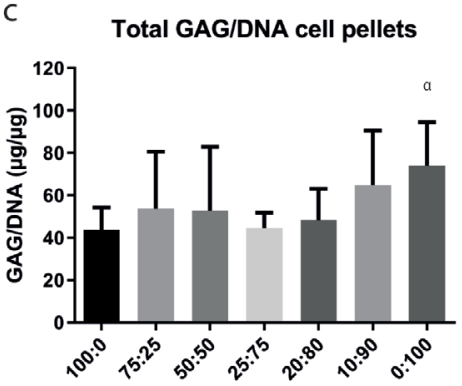

Ratio meniscus cells: MSCs

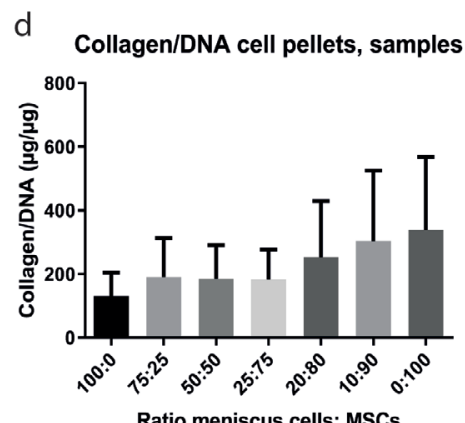

e DNA samples type I collagen hydrogel

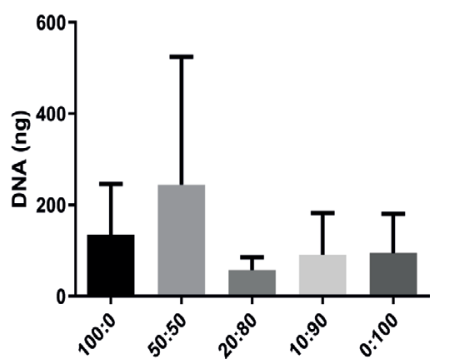

$f_{\text {GAG/DNA samples type I collagen hydrogel }}$

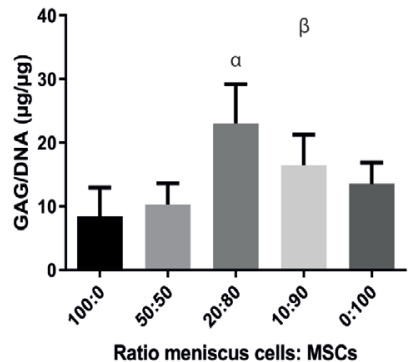

g

Total GAG/DNA type I collagen hydrogel

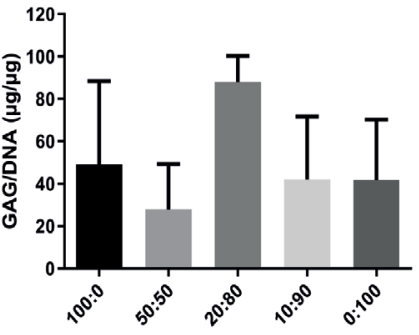

Ratio meniscus cells: MSCs

h

Collagen/DNA type I collagen hydrogel, samples

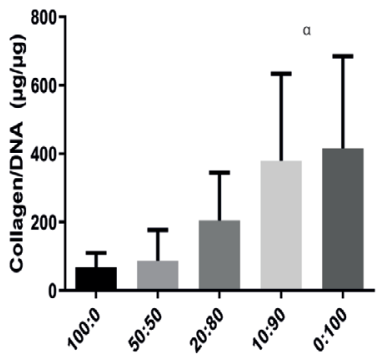

Fig. 3. Biochemical analysis after co-culture of meniscus cells and MSCs in different ratios. (a,e) DNA content, (b,f) GAG content, (c,g) total GAG production and $(\mathbf{d}, \mathbf{h})$ collagen content, all corrected for DNA content, are shown for (a-d) cell pellets and (e-h) co-cultures in type I collagen hydrogel for the different ratios of meniscus cells and hMSCs after $28 \mathrm{~d}$ of culture. Data are shown as mean \pm standard deviation; $p<0.05$. (a) $100 \%$ meniscus cells was statistically higher in DNA content than all the other conditions $(\alpha), 75: 25$ and $50: 50$ were significantly higher than $10: 90$ and $0: 100(\beta$ and $\gamma)$ and $25: 75$ was higher than $0: 100(\delta)$. (b) GAG/DNA in cell pellets was significantly higher in $100: 0(\alpha)$ as compared to $75: 25$, but significantly lower as compared to $25: 75,10: 90$ and $100: 0.75: 25(\beta)$ was significantly lower than $25: 75,20: 80,10: 90$ and $0: 100$. $50: 50(\gamma)$ was significantly lower as compared to $25: 75,10: 90$ and $0: 100$. $100: 0$ was significantly higher as compared to $25: 75$ and $20: 80(\delta$ and $\lambda)$. (c) Total GAG/DNA in cell pellets was significantly higher in $0: 100(\alpha)$ as compared to $100: 0,25: 75$ and $20: 80$. In both (d) collagen/DNA in cell pellets and (e) DNA content in type I collagen hydrogels, no significant differences were detected. (f) In the samples cultured in type I collagen hydrogels, $20: 80$ was significantly higher in GAG/DNA as compared to $100: 0,50: 50$ and $0: 100(\alpha)$ and $10: 90$ was significantly higher than $100: 0(\beta)$. (g) No significant differences were found for total GAG/DNA in the co-cultures using collagen type I hydrogels. (h) Collagen content corrected for DNA in $10: 90$ and $0: 100$ was significantly higher as compared to $100: 0$ and $50: 50(\alpha)$. 


\section{Discussion}

The goal of the present in vitro study was to assess the conditions for a new one-stage cell-based procedure for meniscus regeneration. The study examined the interaction through gap junctions between hMSCs and meniscus cells and demonstrated a short survival period of hMSCs in co-cultures, indicating a stimulating effect of hMSCs on meniscus cells. The optimal ratio for co-culture of MSCs and meniscus cells was reported to be $80 \%$ hMSCs and $20 \%$ meniscus cells, where native-like meniscus tissue, type I collagen and a minimal amount of GAG were produced. Contiguously, the best seeding method for this cell combination into a clinically applicable scaffold was shown to be dry seeding. All these findings suggested that this new treatment method for meniscus regeneration was clinically applicable.

Immunohistochemistry for connexin 43 , dye transfer experiments and PCR results demonstrated transfer of information from hMSCs to meniscus cells by gap junctions and a decrease in the number of hMSCs in time. The low amount of male DNA after 4 weeks of culture, shown by PCR, indicated that MSCs disappeared after stimulating or transferring information to meniscus cells. Liu (2019) has shown that hMSCs can transfer their functional mitochondria into injured endothelial cells after ischemic stroke in mice, protecting the endothelial cells from going into apoptosis. After stimulating meniscus cells, hMSCs seemed to disappear. Xu et al. (2004) have described the function of hMSCs by differentiation into the required cell type in e.g. isolated cartilage defects, osteoarthrosis or after a myocardial infarction. However, de Windt et al. (2015) have shown that the DNA of the newly formed cartilage tissue, in patients treated with a combination of allogenic hMSCs and autologous chondrocytes, does not contain any DNA from the hMSC donor, only from the patient itself. The present study showed that the decrease in co-

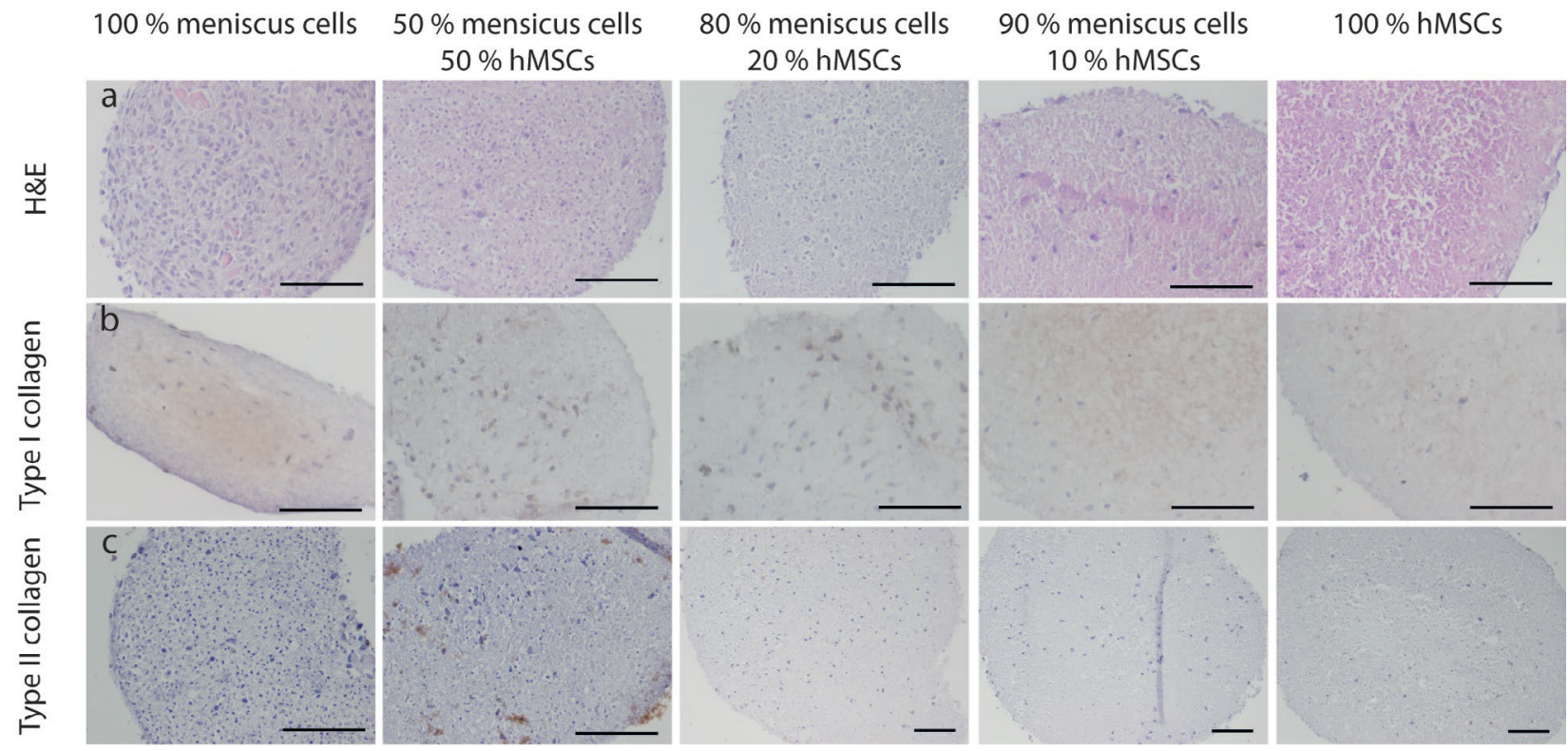

Fig. 4. Histological stainings of pellet cultures of different ratios of meniscus cells and MSCs, 20× magnification. (a) H\&E showed cell concentration in the different ratios. (b) Immunohistochemistry showed staining for type I collagen and (c) almost no staining for type II collagen in all ratios. Scale bar: $100 \mu \mathrm{m}$.

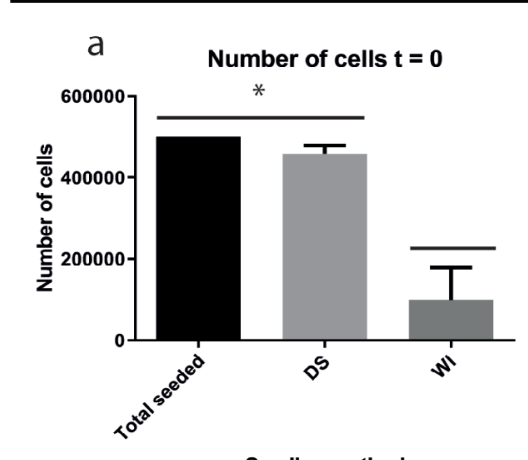

Seeding method
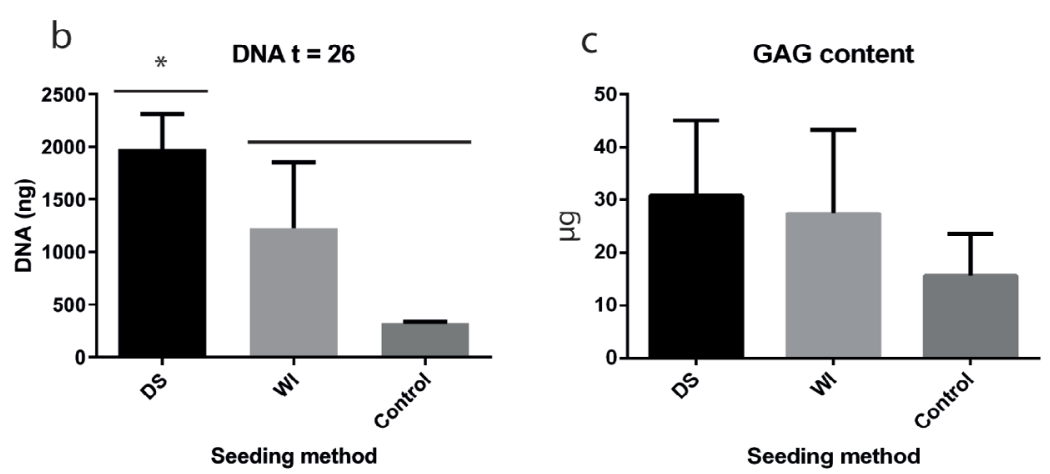

Fig. 5. Number of cells after two different seeding methods. (a) Total number of cells at $t=0 \mathrm{~d}$, (b) DNA content at $\mathrm{t}=26 \mathrm{~d}$ and (c) GAG content for co-cultures of meniscus cells and hMSCs in a 10:90 ratio inside the $\mathrm{CMI}^{\circledast}$ for $26 \mathrm{~d}$ using different seeding methods (dry static and wet-injected, respectively). A CMI ${ }^{\circledR}$ without cells was used as the control group. Data are shown as mean \pm standard deviation; ${ }^{*} p<0.05$. DS = dry seeding; $\mathrm{WI}=$ wet seeding by injection. 
cultures was higher as compared to the decrease in hMSCs monocultures. This, in combination with the results of de Windt et al. (2015), could indicate that, in co-culture, hMSCs might have a more stimulatory effect on the production of GAG and collagen from meniscus cells and contribute less to ECM production and replacement of avital native cells in damaged tissue; whereas, in monoculture, ECM production might be regulated by the hMSCs themselves.

The willingness to use allogeneic hMSCs for future in vivo experiments is reinforced by the possible pro-inflammatory effect triggered by the presence of allogeneic cells in the patient, which might cause a boost in the regenerative effect. Hare et al. (2017) have shown a superior effect of allogenic to autologous hMSCs in patients receiving transendocardial stem cell injections for non-ischemic dilated cardiomyopathy. Such patients have an improved endothelial function, a greater suppression of tumour necrosis factor alpha (TNF- $\alpha$; suggesting a shift towards a less inflammatory phenotype of the immune cells) and clinical better outcomes (Hare et al., 2017).

The present study showed an increase in GAG and collagen production in co-cultures as compared to monocultures of meniscus cells. Co-cultures with a higher percentage of hMSCs resulted in the highest ECM production. Similar results were previously described by Cui et al. (2012) and Matthies et al. (2013). Co-culture results were comparable to the results of co-cultures of hMSCs and chondrons, as shown by Bekkers et al. (2013), with the highest GAG/DNA production in $80 \%$ and $90 \%$ hMSCs, respectively. Nevertheless, monoculture of hMSCs resulted in the highest production of GAG and collagen per DNA, which is not described by others. A possible explanation could be that pellet culture might not be the optimal 3D culture method for ECM production by meniscus cells. In the native meniscus, cells are dispersed throughout the ECM and there is very limited contact between cells. In pellet culture, cells are aggregated together at high density without being surrounded by matrix, especially at the start of the culture. Consequently, results suggested that meniscus cells performed better in 3D hydrogels. This could partially explain the differences in ECM production between meniscus cells and hMSCs. However, Song et al. (2015) have shown less GAG and collagen production by MSCs as compared to co-cultures and monocultures of meniscus cells, similarly to Cui et al. (2012) and Matthies et al. (2013). Besides type of co-culture, the type of MSCs could significantly influence the difference in outcome after in vitro co-culture, as MSCs are a heterogeneous population of cells and their characteristics and regenerative potential is dependent on a variety of parameters, such as donor, location, harvest method, isolation method, expansion density and composition of expansion medium and culture medium (Fellows et al., 2016). MSCs are often poorly characterised, making it challenging to compare the direct results of various studies. Synovium-derived mesenchymal stromal cells (SSC) were used by Song et al. (2015), differently from the marrow MSCs used in the present study. In addition, Song et al. (2015) co-cultured the pellets for a total of 2 weeks, half the time as compared to the current study. Therefore, it could be possible that MSCs started producing more ECM after the first 2 weeks of culture.

Due to the possible negative effect of co-culturing meniscus cells in pellets, the study included coculturing in a type I collagen hydrogel to closer mimic the native environment of the meniscus cells. Results showed a significantly higher production of GAG/ DNA for the $80 \%$ and $90 \%$ hMSC conditions and of total GAG/DNA for the $80 \%$ hMSC condition, with a lower production of GAG in the hMSC monoculture. However, collagen production was hard to determine due to the collagen already present in the hydrogel. Collagen content corrected for DNA showed a significantly higher concentration in the conditions with $90 \%$ and $100 \%$ hMSCs, which could be either
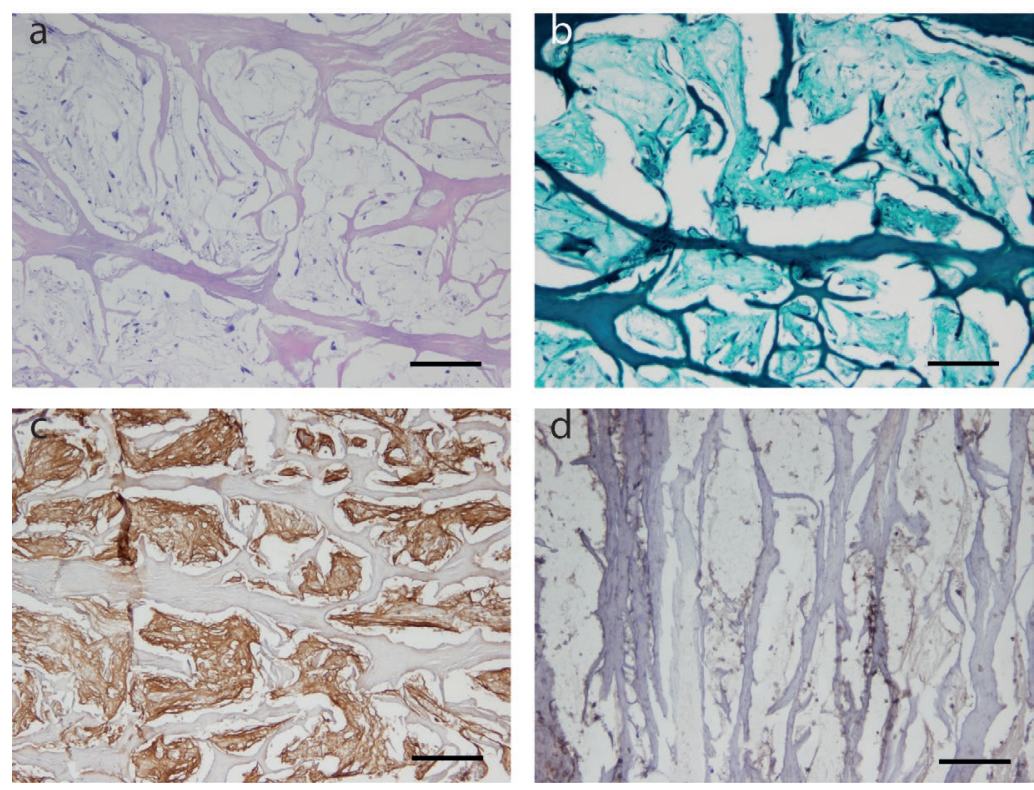

Fig. 6. Histological stainings. (a) $\mathrm{H} \& \mathrm{E},(\mathbf{b})$ safranin $\mathrm{O} /$ fast green and (c) immunohistochemistry for type I and (d) type II collagen of dry-seeded CMI ${ }^{\circledR}$ with a $10: 90$ ratio of meniscus cells and hMSCs, cultured for $26 \mathrm{~d}$. Scale bar: $100 \mu \mathrm{m}$. 
the result of a higher collagen production by hMSCs and/or a higher break down of type I collagen hydrogel by the meniscus cells. These findings were different from those of McCorry et al. (2016), who have shown the highest GAG production in the $50: 50$ ratio. However, McCorry et al. (2016) have used bovine cells, passage 4 MSCs (cultured with fibroblast growth factor) and passage 0 meniscus cells as compared to hMSCs passage 3 and human meniscus cells passage 1 of the current study. In addition, in the present study, co-culture was harvested after $28 \mathrm{~d}$, compared to the $15 \mathrm{~d}$ reported by McCorry et al. (2016). Perhaps, the most important difference is the fixed shape they have used for culturing type I collagen hydrogels, so that the collagen gel could not contract during the culturing period, which also has an influence on ECM production (Vickers et al., 2006; Vickers et al., 2010).

The most frequently-described seeding methods reported in the literature are static seeding, seeding by injection and centrifugal seeding (Godbey et al., 2004; Thevenot et al., 2008; Weinand et al., 2009; Zhang et al., 2015). Most studies are directed towards cell viability and distribution without considering the clinical applicability for a one-stage procedure where seeding of the scaffold has to be performed according to GMP-regulations. Zhang et al. (2015) have reported the best cell distribution of MSCs and meniscus fibrochondrocytes using centrifugal seeding, although these results were not significantly better than static seeding. When static seeding was used, Thevenot et al. (2008) have shown a high cell density in the top layer of the scaffold as compared to the centre and bottom. This result does not compare with the present study results where a homogeneous distribution of cells throughout the whole scaffold in vertical direction was shown. Besides the seeding method, scaffold material could also influence cell numbers and cell distribution after seeding. Demineralised cancellous bone and poly(lactideco-glycolide) (PLGA) scaffolds were used by Zhang et al. (2015) and Thevenot et al. (2008), respectively, having different material characteristics as compared to the $\mathrm{CMI}^{\circledR}$, including pore size. The $\mathrm{CMI}^{\circledR}$ has a wide range of pore sizes $(50-400 \mu \mathrm{m})$, whereas Thevonot et al. (2008) (mean $212 \mu \mathrm{m}$, range 150-250 $\mu \mathrm{m}$ ) and Zhang et al. (2015) $(268 \mu \mathrm{m})$ used a smaller pore size. The smaller pore sizes could possibly negatively influence cell distribution after seeding. Moreover, the $\mathrm{CMI}^{\circledR}$ has a sponge-like structure, absorbing fluids rapidly when seeded onto the scaffold, providing a good distribution of the cells when static seeding is used. Multiple injections (in a wet environment) into the $\mathrm{CMI}^{\circledR}$ creates 'pockets' of cells instead of a homogenous distribution. This result is not illustrated in the literature, since previous authors performed the injected seeding with only one injection (Thevenot et al., 2008; Weinand et al., 2009; Zhang et al., 2015).

\section{Conclusion}

The present study demonstrated the in vitro feasibility of a new one-stage cell-based procedure for meniscus regeneration in young and active patients with non-repairable meniscus tears. In co-culture hMSC stimulated meniscus cells to produce ECM by communication through gap junctions before going into apoptosis. The most optimal ratio for GAG and collagen production was $20 \%$ meniscus cells and $80 \%$ hMSCs. Static seeding resulted in a higher cell density and better cell distribution than wet seeding. The results of these in vitro experiments lay the foundation for clinical application of one-stage cellbased meniscus regeneration procedures.

\section{Acknowledgements}

The authors wish to thank Smith\&Nephew and Ivy Sports Medicine for research funding and iMove Medical for providing research material.
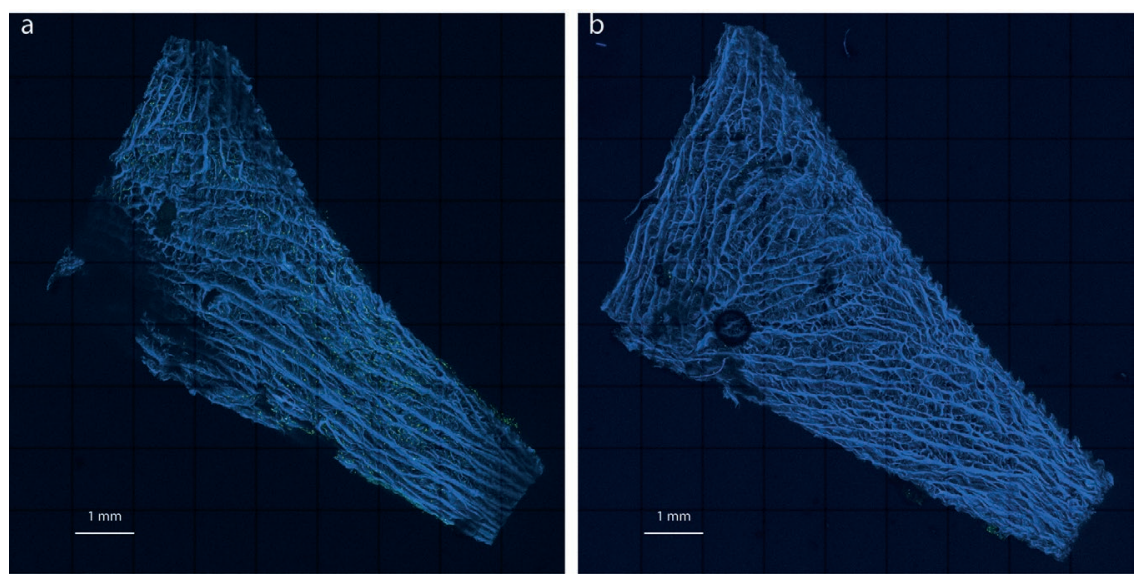

Fig. 7. Cell distribution throughout the $\mathrm{CMI}^{\circledR}$ for different seeding methods. Cells were stained with calcein AM (green) and the CMI ${ }^{\circledR}$ with DAPI (blue). 3D images were taken using a confocal microscope (Leica) showing cell distribution throughout the $\mathrm{CMI}{ }^{\circledR}$ using (a) the dry static seeding method and (b) the wet-injected $\mathrm{CMI}^{\circledR}$. 


\section{References}

Abbadessa A, Mouser VHM, Blokzijl MM, Gawlitta D, Dhert WJA, Hennink WE, Malda J, Vermonden T (2016) A synthetic thermosensitive hydrogel for cartilage bioprinting and its biofunctionalization with polysaccharides. Biomacromolecules 17: 2137-2147.

Bekkers JEJ, Tsuchida AI, van Rijen MHP, Vonk LA, Dhert WJA, Creemers LB, Saris DBF (2013) Single-stage cell-based cartilage regeneration using a combination of chondrons and mesenchymal stromal cells. Am J Sports Med 41: 2158-2166.

Caplan AI, Correa D (2011) The MSC: an injury drugstore. Cell Stem Cell 9: 11-15.

Cui X, Hasegawa A, Lotz M, D'Lima D (2012) Structured three-dimensional co-culture of mesenchymal stem cells with meniscus cells promotes meniscal phenotype without hypertrophy. Biotechnol Bioeng 109: 2369-2380.

Dangelmajer S, Familiari F, Simonetta R, Kaymakoglu M, Huri G (2017) Meniscal transplants and scaffolds: a systematic review of the literature. Knee Surg Relat Res 29: 3-10.

de Windt TS, Vonk LA, Slaper-Cortenbach ICM, Nizak R, van Rijen MHP, Saris DBF (2017a) Allogeneic MSCs and recycled autologous chondrons mixed in a one-stage cartilage cell transplantion a first-in-man trial in 35 patients. Stem Cells 8: 1984-1993.

de Windt TS, Vonk LA, Slaper-Cortenbach ICM, van den Broek MPH, Nizak R, van Rijen MHP, de Weger RA, Dhert WJA, Saris DBF (2017b) Allogeneic mesenchymal stem cells stimulate cartilage regeneration and are safe for single-stage cartilage repair in humans upon mixture with recycled autologous chondrons. Stem Cells 35: 256264.

Englund M, Guermazi A, Lohmander SL (2009) The role of the meniscus in knee osteoarthritis: a cause or consequence? Radiol Clin North Am 47: 703-712.

Federa (2011) Human tissue and medical research: code of conduct for responsible use.

Fellows CR, Matta C, Zakany R, Khan IM, Mobasheri A (2016) Adipose, bone marrow and synovial joint-derived mesenchymal stem cells for cartilage repair. Front Genet 7: 213. DOI: 10.3389/ fgene.2016.00213.

Filardo G, Andriolo L, Kon E, de Caro F, Marcacci M (2015) Meniscal scaffolds: results and indications. A systematic literature review. Int Orthop 39: 35-46.

Fox AJS, Wanivenhaus F, Burge AJ, Warren RF, Rodeo SA (2015) The human meniscus: a review of anatomy, function, injury, and advances in treatment. Clin Anat 28: 269-287.

Gawlitta D, van Rijen MHP, Schrijver EJM, Alblas J, Dhert WJA (2012) Hypoxia impedes hypertrophic chondrogenesis of human multipotent stromal cells. Tissue Eng Part A 18: 1957-1966.

Godbey WT, Stacey Hindy BS, Sherman ME, Atala A (2004) A novel use of centrifugal force for cell seeding into porous scaffolds. Biomaterials 25: 2799-2805.
Grassi A, Zaffagnini S, Marcheggiani Muccioli GM, Benzi A, Marcacci M (2014) Clinical outcomes and complications of a collagen meniscus implant: a systematic review. Int Orthop 38: 1945-1953.

Hagmeijer MH, Vonk LA, Kouwenhoven JW, Custers RJH, Bleys RL, Krych AJ, Saris DBF (2018) Surgical feasibility of a one-stage cell-based arthroscopic procedure for meniscus regeneration. Tissue Eng Part C Methods 24: 688-696.

Hare JM, DiFede DL, Rieger AC, Florea V, Landin AM, El-Khorazaty J, Khan A, Mushtaq M, Lowery MH, Byrnes JJ, Hendel RC, Cohen MG, Alfonso CE, Valasaki K, Pujol M V., Golpanian S, Ghersin E, Fishman JE, Pattany P, Gomes SA, Delgado C, Miki R, Abuzeid F, Vidro-Casiano M, Premer C, Medina A, Porras V, Hatzistergos KE, Anderson E, Mendizabal A, Mitrani R, Heldman AW (2017) Randomized comparison of allogeneic versus autologous mesenchymal stem cells for nonischemic dilated cardiomyopathy. J Am Coll Cardiol 69: 526537.

Liu K (2019) Mesenchymal stem cells transfer mitochondria into cerebral microvasculature and promote recovery from ischemic stroke. Microvasc Res 123: 74-80.

Masouros SD, McDermott ID, Amis AA, Bull AM (2008) Biomechanics of the meniscus-meniscal ligament construct of the knee. Knee Surgery Sport Traumatol Arthrosc 16: 1121-1132.

Matthies NF, Mulet-Sierra A, Jomha NM, Adesida AB (2013) Matrix formation is enhanced in co-cultures of human meniscus cells with bone marrow stromal cells. J Tissue Eng Regen Med 7: 965-973.

McCorry MC, Puetzer JL, Bonassar LJ (2016) Characterization of mesenchymal stem cells and fibrochondrocytes in three-dimensional co-culture: analysis of cell shape, matrix production, and mechanical performance. Stem Cell Res Ther 7: 39. DOI: 10.1186/s13287-016-0301-8.

Mitchell J, Graham W, Best TM, Collins C, Dustine WC, Comstock RD, Flanigan D (2016) Epidemiology of meniscal injuries in US high school athletes between 2007 and 2013. Knee Surg Sport Traumatol Arthrosc 28: 1304-1314.

Neuman ER, Logan AM (1950) The determination of hydroxyproline. J Biol Chem 184: 299-306.

Pabbruwe MB, Kafienah W, Tarlton JF, Mistry S, Fox DJ, Hollander AP (2010) Repair of meniscal cartilage white zone tears using a stem cell/collagenscaffold implant. Biomaterials 31: 2583-2591.

Prockop DJ, Youn Oh J (2012) Mesenchymal stem/stromal cells (MSCs): role as guardians of inflammation. Mol Ther 20: 14-20.

Schepers K, Fibbe WE (2016) Unraveling mechanisms of mesenchymal stromal cell-mediated immunomodulation through patient monitoring and product characterization. Ann N Y Acad Sci 1370: $15-23$.

Song X, Xie Y, Liu Y, Shao M, Wang W (2015) Beneficial effects of coculturing synovial derived mesenchymal stem cells with meniscus 
fibrochondrocytes are mediated by fibroblast growth factor 1: increased proliferation and collagen synthesis. Stem Cells Int 2015: 926325. DOI: $10.1155 / 2015 / 926325$.

Thevenot P, Nair A, Dey J, Yang J, Tang L (2008) Method to anale three-dimensional cell distribution and infiltration in degradable scaffolds. Tissue Eng Part C Methods 14: 319-331.

van Diest PJ (2002) No consent should be needed for using leftover body material for scientific purposes. For against. BMJ 325: 648. DOI: 10.1136/ bmj.325.7365.648.

Verdonk R, Madry H, Shabshin N, Dirisamer F, Peretti GM, Pujol N, Spalding T, Verdonk P, Seil R, Condello V, Di Matteo B, Zellner J, Angele P (2016) The role of meniscal tissue in joint protection in early osteoarthritis. Knee Surg Sports Traumatol Arthrosc 24: 1763-1774.

Vickers SM, Gotterbarm T, Spector M (2010) Cross-linking affects cellular condensation and chondrogenesis in type II collagen-GAG scaffolds seeded with bone marrow-derived mesenchymal stem cells. J Orthop Res 28: 1184-1192.

Vickers SM, Squitieri LEES, Spector M (2006) Effects of cross-linking type II collagen-GAG scaffolds on chondrogenesis in vitro: dynamic pore reduction promotes cartilage formation. Tissue Eng 12: 13451355.

Weinand C, Jian WX, Peretti GM, Bonassar LJ, Gill TJ (2009) Conditions affecting cell seeding onto three-dimensional scaffolds for cellular-based biodegradable implants. J Biomed Mater Res B Appl Biomater 91: 80-87.

de Windt TS, Saris DBF, Slaper-Cortenbach ICM, van Rijen MHP, Gawlitta D, Creemers LB, de Weger RA, Dhert WJA, Vonk LA (2015) Direct cell-cell contact with chondrocytes is a key mechanism in multipotent mesenchymal stromal cell-mediated chondrogenesis. Tissue Eng Part A 21: 2536-2547.

Xu M, Wani M, Dai Y, Wang J (2004) Differentiation of bone marrow stromal cells into the the cardiac phenotype requires intercellular communication with myocytes. 17: 2658-2665.

Zaffagnini S, Grassi A, Marcheggiani Muccioli GM, Holsten D, Bulgheroni P, Monllau JC, Berbig R, Lagae K, Crespo R, Marcacci M (2015) Two-year clinical results of lateral collagen meniscus implant: a multicenter study. Arthroscopy 31: 1269-1278.

Zhang ZZ, Jiang D, Wang S-J, Qi Y-S, Zhang J-Y, $\mathrm{Yu}$ J-K (2015) Potential of centrifugal seeding method in improving cells distribution and proliferation on demineralised cancellous bone scaffolds for tissueengineered meniscus. ACS Appl Mater Interfaces 7: 15294-15302.

\section{Discussion with Reviewers}

Norimasa Nakamura: What is the potential difficulty in transferring this model into an animal model? Authors: Only one animal model is described in the literature (Martinek et al., 2006, additional reference). The authors harvested fibrochondrocytes from sheep $(n=25)$, cultured them in vitro, seeded on $\mathrm{CMI}$ and implanted the seeded scaffolds where the meniscus used to be. An improvement of macroscopic and histological meniscus tissue as compared to implantation of non-seeded CMIs was shown. The study demonstrated that the principle of an animal study for seeded meniscus implants is an option. However, we do not think it will provide us with extra information. In a cadaveric study, Hagmeijer et al. (2018) showed that seeding before implantation of the scaffold results in a larger number of cells in the scaffold, a better distribution and no effect on cell survival as compared to seeding after implantation. de Windt et al. (2016) showed the safety of using allogeneic mesenchymal stromal cells for cartilage regeneration. Therefore, we think an animal model will not add extra evidence for proceeding with this new method of meniscus regeneration.

Reviewer 1: Did the authors isolate meniscus cells from the whole tissue or were the cells obtained from the inner and outer part, respectively? Did the authors perform some experiments to compare the inner and outer cells? In their opinion, could the difference in terms of ECM production be important to achieve the best outcome for the treatment?

Authors: Meniscus cells were isolated from whole meniscus and no difference was made between inner and outer part of the meniscus. No experiment was performed to distinguish between cells from inner and outer part of the meniscus in ECM production. Although, it is likely that there is a difference in ECM production from cells of the inner and outer part of the meniscus as their composition and loading patterns differ and also only the outer meniscus is vascularised. However, the present in vitro study was performed to look at the feasibility of a one-stage cell-based procedure for meniscus regeneration. In a clinical setting for such a procedure, it would be impossible to distinguish between the inner and outer meniscus. Moreover, cells from the torn meniscus would be used, which is automatically the part that needs to be regenerated. Therefore, in our opinion, these types of experiments would not contribute to a better clinical outcome.

\section{Additional Reference}

Martinek V, Ueblacker P, Kraun K, Nitschke S, Mannhardt R, Specht K, Gansbacher B, Imhoff AB. (2006) Second generation of meniscus transplantation: in-vivo study with tissue engineered meniscus replacement. Arch Orthop Trauma Surg 126: 228-234

Editor's note: The Scientific Editor responsible for this paper was Martin Stoddart. 